\title{
Investigative Interviews with Suspects and Witnesses: A Survey of Perceptions and Interview Practices Among Malaysian Police
}

\author{
Kai Li Chung ${ }^{1}$ [ $\cdot$ Magdalene $\mathrm{Ng}^{2,3} \cdot$ I Ling Ding ${ }^{4}$
}

Accepted: 16 November 2020 / Published online: 18 January 2021

(c) The Author(s) 2021

\begin{abstract}
Interviewing of suspects, victims, and eyewitnesses contributes significantly to the investigation process. While a great deal is known about the investigative interviewing practices in the United Kingdom and the Nordic region, very little is known about the framework used by Malaysian police officers. A survey was administered to 44 Royal Malaysian Police interviewers serving in the Sexual, Women and Child Investigations Division (D11) of the Crime Investigation Department. Respondents were asked about the investigative interviewing techniques they use with suspects, witnesses, and victims; how effective they think these techniques are; and the training they had received. Findings revealed that many police officers currently possess limited knowledge of best practice investigative interviewing. More training, feedback, and supervision is needed and desired.
\end{abstract}

Keywords Investigative interviewing $\cdot$ Suspects $\cdot$ Witnesses $\cdot$ Police practice $\cdot$ Police training

\section{Introduction}

In the criminal justice system, the main purpose of a forensic investigation is to gather information about what happened (if anything did indeed happen), as well as to find out who did what (Milne and Bull 2006). Particularly when investigating officers have little or no forensically relevant information, the interviewing of suspects, witnesses, and victims becomes a key element in the process of an investigation. The objective of investigative interviews is to elicit an accurate, complete, and detailed record of the original account from an interviewee.

\section{Interviewing of Suspects}

Over the past few decades, investigative or forensic interviewing in the United Kingdom and the Nordic region has

Magdalene $\mathrm{Ng}$

magdalene.ng@newcastle.ac.uk

Kai Li Chung

k.chung@ reading.ac.uk

1 University of Reading, Nusajaya, Malaysia

2 HELP University, Kuala Lumpur, Malaysia

3 Newcastle University, Urban Sciences Building, 1 Science Square, Newcastle upon Tyne NE4 5TG, UK

4 Royal Malaysian Police, Kuala Lumpur, Malaysia moved away from a confession-seeking 'interrogating' exercise to more of an information-gathering 'inquiry' process, indicating an advocacy for a less confrontational approach (Rabon 1992). Changes in legislations and practices in these regions were brought about in part due to a number of highprofile miscarriages of justice (e.g. the Guildford Four in England) that emerged from police malpractice and poor interviewing of suspects before the 1980s (Gudjonsson 1992). Following the enactment of the Police and Criminal Evidence Act in the United Kingdom in 1984 whereby tape recording of suspect interviews was made mandatory, the investigative interviewing process became more widely accessible and allowed for more research examining interviewer and interviewee behaviour (e.g. Baldwin 1992). Nevertheless, initial analyses of the tape recordings revealed some shortcomings of the interview process, including lack of preparation; poor techniques such as prolonged, repetitive, and/or coercive questioning; and general ineptitude of the interviewer (Milne et al. 2007).

It was evident that a change of investigative culture was needed to restore confidence in evidence obtained through police questioning. As a result, the PEACE interviewing model, underpinned by psychological principles and theories, was devised in the early 1990s, setting out principles and best practices in questioning suspects and witnesses (Milne et al. 2007). PEACE is an acronym that outlines the structure of the interview: preparation and planning 
of the interview, engage and explain, account, closure and evaluation. This model endorses a critical element of the investigative interviews, which is the use of non-leading, open-ended questions (Milne and Powell 2010). Non-leading questions refrain from directing respondents toward a particular answer. Open-ended questions are those that require more thought, as opposed to a static one-word response. These questions are useful for interviewees to maximise the opportunity to provide a full account, while minimising confusion and contamination.

The PEACE framework of interviewing signifies the departure from psychologically manipulative and accusatorial approaches that have been associated with false confessions. It is generally accepted that the implementation of the PEACE model (and similar models adopted in several other countries) has resulted in enhanced police interviewing practice (Bull and Rachlew 2020; Clarke et al. 2011; Griffiths and Milne 2006).

\section{Interviewing of Child Victims and Witnesses}

In most cases of child sexual or physical abuse, the victim is usually the only available sources of information, which often means that the progress of the inquiry will rely upon the child's narrative. Children are often perceived to be less competent than adults when it comes to remembering incidents they have experienced, and their testimony tends to be dismissed in court due to this perceived lack of credibility. Whilst there is a general consensus that child age is a robust predictor of memory accuracy and completeness (Peterson 2012), some studies have shown that children have the capacity to provide accurate information about their stressful past experience (e.g. Baugerud et al. 2014). Important factors that influence the quantity and quality of information provided are the interviewer's ability to elicit information and the child's readiness and capacity to express it, rather than the child's ability to remember it (Lamb et al. 2007). In other words, there is a shared view by academics and practitioners alike that a realistic awareness of children's developmental level, combined with careful investigative procedures, may enable valuable information to be obtained (Poole and Lamb 1998). On top of this, one of the most common problems is the lack of appropriate systems in place to enable child victims or witnesses to describe their traumatic experiences accurately. Improper interviewing techniques can be counterproductive, leading to distorted memory and contaminated testimony (Bruck and Ceci 1999). Consequently, children go through long and complicated legal processes only to have experts later testify that interview outcomes were inconclusive; misunderstandings may result in wrongful convictions or family break-ups; and what is worse, child abusers run free to exploit others (Ananthalakshmi 2016).
Of the various protocols designed to safeguard children's welfare whilst facilitating best evidence, the National Institute of Child Health and Human Development (NICHD) Investigative Interview Protocol developed by Lamb et al. (2007) is one that has been supported by empirical evidence and serves as a model for protocols in many countries ( $\mathrm{La}$ Rooy et al. 2015). The NICHD protocol starts with the presubstantive phase, in which the interviewer introduces his/ her role, clarifies the child's task, and explain the ground rules. This phase also includes rapport-building and training in episodic retrieval. Next, non-suggestive prompts are used to allow the child to introduce to the target incident under investigation; if the child fails to identify the target incident, carefully worded focussed prompts are used. The interviewer then moves on to the substantive phase, using open-ended invitations to enable the child to give details about the event, following which open-ended cues are used as appropriate. Specific, more focussed questions (e.g. "wh-" or optionposing) may be used if crucial details are still missing. In the final closing phase, the child is given an opportunity to provide any other information, after which a neutral topic is discussed.

In general, field studies have shown that investigative interviewers who adhere to the recommended interview procedures of the NICHD protocol are able to obtain more informative details from alleged victims of sexual or physical abuse, but follow-up training sessions and continuing supervision seem to be important for maintaining the quality of forensic interviewing (e.g. Cyr and Lamb 2009; Lamb et al. 2002).

\section{The Present Study}

It is clear that considerable efforts have been made over the years to enhance investigative interviewing standards and increase transparency based on psychological science. However, in many countries, arguably including Malaysia, police interviewing is still deemed as an inherent skill that all investigating officers possess, and can be acquired through learning from the more experienced (Milne et al. 2007). The discussions above highlight the importance of using careful investigative procedures to ensure that testimony of the suspect, victim, or eyewitness is not contaminated in any way. It is therefore extremely important that officers are being properly equipped with the support and tools necessary to be competent to carry out investigative interviews professionally and ethically. If proper investigative interview methods are put in place, miscarriages of justice can be prevented (Kassin and Gudjonsson 2004; Otgaar and Howe 2019). After all, forensic interviewing is a highly specialised skill, and the ability to elicit accurate and detailed information is 
one that can be mastered through ongoing training, proper supervision, and appropriate feedback (Powell et al. 2010).

Currently, very little is known about the interviewing framework used by Malaysian police officers to conduct interviews with suspects, witnesses, and victims. There are no published studies in Malaysia that have evaluated the accessibility and effectiveness of the police and legal services (Cheah and Choo 2016). In light of this lack of information, the aim of this survey is to gain insight into Malaysian investigative officers' perceptions and practices regarding investigative interviewing with suspects, victims, and witnesses. Respondents were asked about their perceptions of the effectiveness of various investigative interviewing techniques, their perceived operational skills and competence in investigative interviewing, and the training and supervision they had received.

\section{Method}

\section{Participants}

The questionnaires were distributed to 90 investigating officers from the Royal Malaysian Police Perak State Contingent Crime Investigation Department, but 46 (51.1\%) non- or partial-responses were excluded from the analyses; hence, there were data for a total of 44 participants, 17 males, 26 females, and one did not reveal their gender, aged 23 to $58(M=32.9, S D=7.7)$. The majority of the sample were ethnic Malay (84.8\%), followed by ethnic Indian (8.7\%), ethnic Chinese (2.2\%), and mixed ethnicities (4.3\%). The mean length of service was 8.3 years $(S D=7.5$ years, range $=1.3-38.3$ years).

\section{Materials}

The pen-and-paper questionnaire was derived, adapted, and translated to Bahasa Malaysia (the official language of Malaysia) from questionnaires used by Hill and Moston (2011) as well as La Rooy et al. (2011). The Bahasa Malaysia version was then reviewed and back-translated. The adapted questionnaire comprised a combination of tick-box style and open-ended questions, requiring participants to provide quantitative and qualitative information on the following sections:

1. Information about the interviewers, including age, gender, ethnicity, language spoken, rank, length of service, previous training in investigative interviewing.

2. Interviewers' perceptions and practices regarding interviews with suspects, including confidence in their ability to detect deceit and truth, what they believe was the main purpose for conducting investigative interviews with suspects, and specific interview components such as open-ended questioning and video-recording.

3. Interviewers' perceptions and practices regarding interviews with child witnesses or victims, including self-review of electronic-recorded interviews, and specific interview components such as rapport-building, communicating ground rules, and the use of props.

4. Further comments from interviewers about their experience and training.

\section{Procedure}

The questionnaires were administered to the investigating officers prior to a talk the researchers were invited to deliver. Respondents were not required to identify themselves in the survey. After reading the participant information sheet, they indicated their consent to take part by ticking a box on the consent form. This project was reviewed and approved by the XXXXHELP University Ethics Review Board and the University of ReadingXXX School of Psychology and Clinical Language Sciences Research Ethics Committee.

\section{Results}

\section{Investigative Interviewing Skills, Training, and Supervision Received}

Overall, 28 respondents (63.6\%) have received some form of investigative interviewing training (i.e. Investigation Course, Child Interview Centre Recording and Interviewing Officer Course), while 16 (36.4\%) reported that they had no training whatsoever before carrying out formal interviews with suspects, victims, and witnesses. Only three respondents (6.8\%) had received Cognitive interview training and four $(9.1 \%)$ reported to have been trained in the PEACE protocol. Eighteen respondents (40.9\%) indicated that they had taken refresher type courses, while 26 respondents (59.0\%) did not. The rest did not provide a response. Participants who have received prior training were trained locally and centrally by senior officers at headquarters.

When asked how often they receive feedback about their interviewing performance from other interviewers and/ or supervisors, $18.2 \%$ answered 'rarely', $45.5 \%$ answered 'occasionally', $20.5 \%$ answered 'never', $11.4 \%$ answered 'always', and only $4.6 \%$ answered 'often'. About a third of the respondents (36.4\%) have not undertaken any informal or self-development training, but $18.2 \%$ have done their own practical training (e.g. role-playing with colleagues), $15.9 \%$ have conducted their own research, and $13.6 \%$ have taken relevant subjects at a learning institution, while the rest did not provide a response. 
Respondents rated their current investigative interviewing skills on a five-point Likert scale $(1=$ poor, $5=$ excellent $)$. About two thirds of the respondents (61.4\%) rated their skills as 'average'. One fifth $(22.7 \%)$ rated their skills as 'above average', while only $6.8 \%$ thought they were 'excellent'. Very few officers rated their skills as 'below average' (6.8\%) or 'poor' $(2.3 \%)$, while 2 officers did not provide a response.

\section{Importance of Investigative Interviewing}

Respondents were asked to report what type of evidence is considered as the central lead in solving a criminal investigation and were allowed to choose more than one option as their answers. Many respondents $(77.3 \%)$ thought that physical evidence were the most important leads in solving investigations, about a third (65.9\%) thought formal interviewing produces the most leads in an investigation, and a small number $(6.8 \%)$ stated that expert reports were most important.

The majority of participants (86.4\%) thought investigative interviewing was 'very important' in progressing an investigation, while a few (13.6\%) rated investigative interviewing as 'important' and 'moderately important'. No respondents rated investigative interviewing as 'not important'.

\section{Suspect Interviews}

On average, respondents had been conducting formal interviews with suspects for 3.3 years $(S D=2.8$ years, range $=0.3-4$ years). Almost all respondents $(90.9 \%)$ interview suspects as a lead interviewer capacity as part of their current duties. The rest assist in these interviews. Approximately half of the respondents (47.7\%) did not feel that existing training equipped them well at all, one third (34.1\%) felt unsure, and only $18.2 \%$ were positive that the training they have had equipped them well.

When asked if they believed that they can detect deception during a formal interview with a suspect, the majority (79.5\%) reported 'yes' while the remainder reported 'no'.

Table 1 Police officers' confidence in detecting truth and lies

\begin{tabular}{llc}
\hline Self-rating & \multicolumn{2}{l}{ Percentage of respondents $(\%)$} \\
\cline { 2 - 3 } & $\begin{array}{l}\text { Skills in detecting } \\
\text { lies }\end{array}$ & $\begin{array}{l}\text { Skills in } \\
\text { detecting } \\
\text { truth }\end{array}$ \\
\hline Very confident & 13.6 & 9.1 \\
Confident & 27.3 & 27.3 \\
Moderately confident & 29.5 & 18.2 \\
Somewhat confident & 27.3 & 40.9 \\
Not at all confident & 2.3 & 4.5
\end{tabular}

Respondents were also asked to report their confidence in lie and truth detection, measured on a 5-point Likert scale. Results are displayed in Table 1.

When probed about what they based their assumptions on when determining truth and deception, $45.5 \%$ answered 'non-verbal behaviour', 63.6\% answered 'verbal behaviour', and $65.9 \%$ answered 'evidence at hand'. There was an 'other' option where respondents could report what influenced their decisions when determining truth and deception. Responses given here include suspect's story and background, eyewitness statement, and suspect's responses to repeated questioning. The percentages do not total to $100 \%$ as participants were allowed to choose more than one response option.

Respondents were asked about the amount of time they typically put into planning prior to conducting a formal suspect interview. About a quarter $(27.3 \%)$ do not spend any time planning the interviews, $18.2 \%$ spend up to $15 \mathrm{~min}$, $22.7 \%$ spend up to $30 \mathrm{~min}, 11.4 \%$ spend up to an hour, $18.2 \%$ spend about 1 to $2 \mathrm{~h}$. No respondents reported spending more than $2 \mathrm{~h}$ on planning and preparing. Most respondents indicated that they never $(29.5 \%)$ or rarely $(47.7 \%)$ experienced time pressures to complete a suspect interview, although a minority $(20.4 \%)$ reported that they usually or almost always did.

Respondents were asked to report the techniques they use when formally interviewing a suspect. Overall, respondents report a mixture of appropriate and inappropriate techniques, as shown in Table 2.

Table 3 displays the frequencies in which officers engaged in specific interview techniques when interviewing suspects, while Table 4 shows their perceptions regarding the extent

Table 2 Police officers' use of interviewing techniques

\begin{tabular}{lc}
\hline Interviewing techniques & $\begin{array}{l}\text { Percentage of } \\
\text { respondents }\end{array}$ \\
\hline "Appropriate" & 70.5 \\
Open questions & 50.0 \\
Emphasising contradictions & 81.8 \\
Gentle prods & 36.4 \\
Concern & 15.9 \\
Silence & 59.1 \\
Disclosure of evidence & 11.4 \\
Challenging the suspect's account & \\
"Inappropriate" & 4.5 \\
Intimidation & 13.6 \\
Interruptions & 29.5 \\
Suggest scenario & 38.6 \\
Situation futility & 13.6 \\
Leading questioning & 50.0 \\
Maximisation of offence & 22.7 \\
Minimisation of offence & 40.9 \\
Repetitive questioning & 9.1 \\
Positive confrontation & 63.6 \\
Handling the suspects mood & \\
\hline
\end{tabular}


Table 3 Frequencies in which police officers engage in specific interview techniques when interviewing suspects

\begin{tabular}{lccccc}
\hline Interview techniques & \multicolumn{7}{l}{ Percentage of respondents } & \\
\cline { 2 - 5 } & Never & Rarely & Usually & Almost always & Always \\
\hline Build rapport & 6.8 & 20.5 & 43.2 & 13.6 & 15.9 \\
Provide full account & 9.1 & 18.2 & 50.0 & 6.8 & 13.6 \\
Specific wh- questions & 0 & 0 & 50.0 & 13.6 & 36.4 \\
Closed yes/no questions & 2.3 & 6.8 & 40.9 & 25.0 & 25.0 \\
Leading questions & 13.6 & 27.3 & 38.6 & 2.3 & 18.2 \\
\hline
\end{tabular}

to which the various techniques helped them find out what had happened.

When probed what these rapport techniques are, there were a mixture of responses. Some respondents expressed disbelief towards the effectiveness of rapport-building ('I've never used rapport; it never works at all'). A number of officers offer food and beverages, or even cigarettes to build goodwill, 'to comfort them' 'so that the suspect relaxes and cooperate'. Some approaches include showing an interest in the suspect in order 'to know what's going on'. A couple of respondents reported using minimisation tactics as part of developing rapport ('if you tell the truth I will make sure to help you reduce your sentence').

Almost half of the respondents $(47.7 \%)$ favoured the videotaping of interviews, $36.4 \%$ were 'neutral', while $15.9 \%$ did not agree to recording such interviews.

\section{Child Witness/Victim Interviews}

On average, $70.5 \%$ of respondents interview child witnesses/victims as a lead interviewer capacity as part of their current duties, while $25.0 \%$ assist in such interviews. A small number of officers $(4.6 \%)$ do not perform witness interviews at all, so they did not answer this part of the survey. On average, respondents had been conducting formal child witness/victim interviews for 3.12 years $(S D=3.2$ years, range $=0.1-14$ years $)$. When asked about whether respondents felt that their interview training equipped them with the necessary skills to conduct child witness/victim interviews effectively, $6.8 \%$ answered 'not at all', $27.3 \%$ answered 'somewhat', and $36.4 \%$ answered 'maybe'. Less than a quarter of participants $(22.7 \%)$ felt that the current training they have definitely equipped them well for conducting child interviews effectively.

Respondents reported spending various amounts of time on planning and preparation, with $15.9 \%$ not spending any time at all, $13.6 \%$ spending up to $15 \mathrm{~min}, 29.6 \%$ spending up to $30 \mathrm{~min}, 2.3 \%$ spending up to $45 \mathrm{~min}, 13.6 \%$ spending up to an hour, and $18.2 \%$ spending more than an hour. About two thirds of respondents indicated that they never $(29.5 \%)$ or rarely $(36.4 \%)$ experienced time pressures to complete a child interview, with a quarter of respondents $(27.3 \%)$ reporting that they usually or almost always did.

Unlike formal interviews with suspects, child interviews are video-recorded in Malaysia. While more than half the respondents 'always' or 'usually' (54.6\%) selfreview their own electronic-recorded interviews with child witnesses/victims, 38.6\% 'rarely' or 'never' self-review the recorded interviews.

Table 5 displays the frequencies in which officers engaged in specific interview techniques when formally interviewing a child witness/victim, while Table 6 shows their ratings of the effectiveness of the various practices in helping them find out what had happened.

Most interviewers establish rapport through friendly communication, asking questions about themselves (e.g., hobbies), showing them cartoons, giving sweets, giving encouragements, among others. Several respondents equated asking questions as part of rapport-building ('Can you tell me what happened?'); one respondent even reported using leading questions ('Is it true that the man put his finger in your private part or did he just touch?').

More than half of the respondents $(56.8 \%)$ use anatomical dolls for child interviews, with a majority of them finding
Table 4 Police officers' ratings of the effectiveness of specific interview techniques when interviewing suspects

\begin{tabular}{llclll}
\hline Interview techniques & \multicolumn{5}{l}{ Percentage of respondents } \\
\cline { 2 - 6 } & $\begin{array}{l}\text { Not at all } \\
\text { effective }\end{array}$ & $\begin{array}{l}\text { Not very } \\
\text { effective }\end{array}$ & Quite effective & Very effective & Always effective \\
\hline Build rapport & 4.5 & 6.8 & 56.8 & 20.5 & 11.4 \\
Provide full account & 0 & 11.4 & 61.3 & 15.9 & 11.4 \\
Specific wh- questions & 0 & 4.5 & 43.2 & 25.0 & 27.3 \\
Closed yes/no questions & 0 & 6.8 & 56.8 & 18.2 & 18.2 \\
Leading questions & 4.5 & 15.9 & 52.3 & 15.9 & 11.4 \\
\hline
\end{tabular}


Table 5 Frequencies in which police officers engage in specific interview techniques when interviewing children

\begin{tabular}{lccccc}
\hline Interview techniques & \multicolumn{5}{l}{ Percentage of respondents } \\
\cline { 2 - 5 } & Never & Rarely & Usually & Almost always & Always \\
\hline Build rapport & 6.8 & 2.3 & 34.1 & 15.9 & 34.1 \\
Ground rules & 4.6 & 9.1 & 45.5 & 11.4 & 22.7 \\
Provide true account & 4.6 & 6.8 & 29.6 & 25.0 & 27.3 \\
Provide full account & 11.4 & 9.1 & 47.7 & 9.1 & 15.9 \\
Specific wh- questions & 2.3 & 4.6 & 50.0 & 9.1 & 27.3 \\
Closed yes/no questions & 2.3 & 6.8 & 45.5 & 9.1 & 27.3 \\
Leading questions & 11.4 & 13.6 & 40.9 & 11.4 & 15.9 \\
\hline
\end{tabular}

this an effective way of getting more information about what happened (77.3\%). The majority of respondents $(56.8 \%)$ do not use other props or object in their formal interviews with children. Those who do use props or objects reported that they use mobile phones, sweets, paper, colour pencils, and cartoons.

\section{Overall Comments on Investigative Interviewing}

One common theme was the need to attend courses and practical training for investigative interviewing practices to improve effectiveness. One respondent noted that 'trainings need not be too long; it's enough to just know the theories and techniques because the investigative interviewer will learn through each case that they receive'.

Respondents also stressed the need to have different approaches when it comes to interviewing suspects as opposed to interviewing child witnesses of victims, through the understanding of psychology and the application of such knowledge.

\section{Discussion}

To the researchers' knowledge, this is the first study that examines the investigative interview practices and perceptions of police officers in Malaysia. This study provided valuable insights in understanding the longer-term needs of Malaysian police officers. The findings obtained seem to stress a need to establish a systematic investigative interviewing framework whereby professionals working with suspects, victims, and witnesses are properly trained to conduct investigative interviews.

One notable strength of this study is that it was not based on samples drawn from Western, educated, industrialised, rich, and democratic (WEIRD) societies (Henrich et al. 2010), instead it was conducted in Malaysia, a Southeast Asian country with a complex multiracial Asian population. According to the Hofstede's (1980) cultural dimension theory (see also Hofstede 2011), Malaysia is considered a collectivistic society with a high power distance. Not only are people in such societies likely to accept and operate under a hierarchical structure, but they also tend to suppress their own interests and opinions to maintain social harmony. It has been put forward by Leal et al. (2018) that during an interview, individuals from collectivistic cultures tend to leave many things unsaid, assuming that the context will communicate what is implied, while on the contrary, individuals from individualistic cultures tend to be more explicit and direct in their communication. Moreover, high power distance societies tend to give less attention to rapport-building (Hofstede 1980), which may stand in the way of the current recommended best practices in investigative interviewing. As such, it is expected that the conduct of investigative interviewing in Malaysia will
Table 6 Police officers' ratings of the effectiveness of specific interview techniques when interviewing children

\begin{tabular}{llllll}
\hline Interview techniques & \multicolumn{4}{l}{ Percentage of respondents } & \\
\cline { 2 - 6 } & $\begin{array}{l}\text { Not at all } \\
\text { effective }\end{array}$ & $\begin{array}{l}\text { Not very } \\
\text { effective }\end{array}$ & Quite effective & Very effective & Always effective \\
\hline Build rapport & 0 & 4.5 & 45.5 & 27.3 & 13.6 \\
Ground rules & 2.3 & 4.5 & 52.3 & 22.7 & 11.4 \\
Provide true account & 2.3 & 6.8 & 45.5 & 22.7 & 15.9 \\
Provide full account & 9.1 & 6.8 & 40.9 & 20.5 & 15.9 \\
Specific wh- questions & 2.3 & 4.6 & 45.5 & 22.7 & 15.9 \\
Closed yes/no questions & 2.3 & 4.6 & 43.2 & 29.6 & 13.6 \\
Leading questions & 6.8 & 4.6 & 56.8 & 15.9 & 6.8 \\
\hline
\end{tabular}


differ substantially from where the concepts of evidencebased investigative interviewing were derived from, that is, highly individualistic nations that sit in the lower rankings on Hofstede's power distance index. For instance, Anakwah et al. (2020) suggested that in collectivistic cultures, investigative interviewers may be required to prompt interviewees to elaborate further on the initial information they provide. The current findings should be interpreted with the understanding that the cultural setting in which an investigative interview has taken place may influence the way information is elicited.

It is worth noting at the outset of this discussions that the Royal Malaysia Police is a federal institution with a centralised, hierarchical model. The Inspector General of Police at headquarters directs operations in 14 regions across the country, but the bulk of the policing lies with the respective states and territories. Whilst there are Crime Investigation Department officers operating at different contingents, formal training is largely central.

Based on the responses received, there were potential concerns about interviewing practices. Almost half of the officers indicated that they had not received formal training or additional 'refresher' courses, even though almost all of them conduct investigative interviews with suspects and/ or children as lead interviewers. Investigative interviewing is a demanding and specialised area, requiring a broad comprehension of psychological aspects, including memory, cognitive biases, and suggestibility. Having access to up-todate training is crucial to ensure that interviewing practices are evidence-based and reflect the current understanding of forensic interviewing. While several respondents may not yet see the value of having longer and repeated training sessions, improvement in interviewing practice may only be observed following refresher training (Rischke et al. 2011). It is acknowledged that it takes time for trainees to consolidate new information and integrate skills into practice; nevertheless, Rischke et al. (2011) asserted that training programmes that space learning, in which materials are reviewed at regular intervals, may be more effective at encouraging maximum information retention and behaviour change.

Moreover, while the majority of interviewers viewed the interview process to be a very important part of the investigation process, many rated their own interviewing skills as average. The fact that both trained and untrained officers report their proficiency as average may point towards a lack of confidence in their investigative interviewing practice. It also appears that there is little evidence of routine supervision on the quality of interviews. As suspect interviews are not recorded, there is limited opportunity for interviewers to review their practice and obtain feedback. These findings serve to further highlight a deficit in investigative interviewing training, likely due to the lack of financial resources for appropriate expertise and facilities to support such activities. That being said, a small number of participants in the current sample reported an initiative in gaining more information about evidence-based investigative interviewing techniques that works. They exhibited an interest in role-playing interviews with fellow colleagues as part of the practical training process and to receive feedback.

An inadequacy of training and implementation of a structured, standardised guide may have led to some unintended consequences. It is not surprising that officers still engage in inappropriate methods of investigative interviewing, with approximately half the respondents in the current sample indicating that they have used maximisation tactics and repetitive questioning in at least one of their interviews with suspects. Similarly, a substantial percentage of participants reported using suggestive questioning in their child interviews and thought this was an effective technique. The present data reflects a pattern that is similar to that seen in other countries prior to the introduction of structured and evidence-based protocols (e.g. Baldwin 1993). For instance, a study conducted by Sumampouw et al. (2020) in Indonesia, a neighbouring country that shares many cultural similarities with Malaysia, reported that police interviewers who have not been trained in an evidence-based protocol used directive and option-posing questions extensively in child forensic interviewing. It is now established that tactics such as maximisation and situation futility are problematic in that they increase a one's susceptibility to false confessions (Kassin 2014), whereas the use of leading or suggestive questions that implies a desired response tends to yield information of poorer quality (Loftus 2005; Sharman and Powell 2012).

With regard to deception detection, more than half of the present sample were confident that they can detect deceit during a suspect interview. Interestingly, many attributed their lie detection ability to non-verbal cues, despite research to date showing that not only the relationship between nonverbal behaviour and deception is faint and unreliable, people also often overestimate their ability to detect deception (for a review, see Vrij et al. 2019). Non-verbal lie detection techniques remain popular among investigators even when there is no clear evidence that they actually work. Misjudging deception can cause innocent people to suffer unjust punishment; it is therefore important to highlight gaps in non-verbal deception research in order to ensure that practitioners are engaging in evidence-based practice, as well as to prevent miscarriages of justice. Continuous training is crucial to enhance practitioners' knowledge and understanding of investigative interviewing.

Building and maintaining rapport during investigative interviewing is said to enhance trust, produce more cooperation, overcome resistance, which can in turn increase the amount of information provided by suspects, witnesses, 
or victims (Collins et al. 2002). However, the present data shows that many interviewers are unable to define critical elements of rapport clearly, which is unsurprising given that even researchers within the field have yet to achieve definitional clarity of the construct (Saywitz et al. 2015). There is therefore a need to further refine its operationalisation, and to test its effects through empirical research.

In relation to the use of props in child interviews, there has not been consistent evidence that forensic interviewing aids such as anatomical dolls improve children's ability to produce more accurate details without elevating the risk of erroneous reporting (Poole et al. 2011). In fact, guidelines in several countries (e.g., Sweden) strongly advise against the use of props or objects. However, the use of anatomical dolls appears to be prevalent in practice according to the current data. Practitioners often report specific barriers relating to forensic interviews with very young children and the necessity to modify existing protocols, which signifies a need for additional guidelines for this age group (Magnusson et al. 2020). To be able to come up with standardised guidelines that are empirically validated and fit for purpose, researchers should take into account concerns raised by investigative interviewers.

A substantial percentage of respondents endorsed the video-recording of interviews with criminal suspects, and many interviewers in the current sample review their own recordings of child interviews. Electronic recording of interviews provides veridical documentation of the interview procedures and individuals' statements. This is promising, as it has been shown that video-recording may inhibit the use of certain confrontational interrogation tactics that could increase the risk of false confessions in suspects, including maximisation and minimisation (Kassin et al. 2014). Having recorded interviews also makes it possible for interviewers, supervisors, and trainers to appraise existing interview practices and facilitate professional development.

While there are decades of scholarship by researchers, social scientists, and clinicians on best ways to elicit comprehensive and accurate information from suspects, witnesses, and victims, the transfer of knowledge to practitioners have not always been successful, evident through the failure of agencies to align their practices with evidence-based recommendations. The lack of investment in adequate and appropriate training makes it very challenging to translate robust research findings into policies and practices in the field. Expert interviewing skills can only be developed through practice and routine guidance, it is thus important for forensic interviewers to train and utilise best practice strategies consistently, enabling them to recognise instances of poor practice and work towards improving standards. According to Lamb (2016), the key players in the criminal justice system, namely the police force, social service agencies, prosecutors, defence lawyers, and judges, need to be aware that the quality of testimony is heavily depended upon the interviewers' ability to elicit information. Only when this fact is widely acknowledged that policy makers will push for improvements in the investigative interviewing process.

\section{Limitations}

The current sample was drawn from one of the thirteen states in Malaysia as a result of convenience sampling, as the researchers were invited to deliver a talk in the Perak state contingent as part of a 'Sexual and Child Abuse Investigation Training Course' for the investigating officers in the Crime Investigation Department. The police officers who attended the training course were from the Sexual, Women and Child Investigations Division (D11), limiting the sample to investigators who primarily handle criminal cases involving sexual and domestic abuse. Whilst the small sample size may not be representative of the entire Malaysian police population, it is likely to be indicative of the situation in the Perak state.

As the data is based on self-report measures, what interviewers say they do may not necessarily reflect their actual interviewing practices, and can be biased by social desirability effects or difficulties in estimating own behaviour. Nevertheless, survey data is valuable in providing insights into the knowledge and perceptions of practitioners.

\section{Conclusion}

This survey provides a first glimpse of investigating interviewing practices in a country in South East Asia. Findings highlight, at least for one investigation unit in Malaysia, that investigative interviews conducted by police officers are not always guided by best practice protocols. Techniques that are inappropriate for forensic purposes contaminate and compromise testimony, which may impede the progress of investigations, risk injustice for the people involved, and fuel public's distrust of the police. On the assumption that the current findings are generalisable to other police units in Malaysia, critical effort should be placed in educating the police force of best practices that will effectively and justly maximise information disclosure in these interviews. This calls for a revision of the current training procedures and an implementation of standardised guidelines in how investigative interviews should be conducted. Collaborations and discussions between practitioners and academics should also be encouraged, as this will help researchers better understand the needs of serving the police force and help set future research agendas. 
Acknowledgements Special thanks to the Perak State Contingent's Sexual, Women and Child Investigations Division of the Crime Investigation Department, Royal Malaysian Police for their support towards this project.

Funding The author received no financial support for the research, authorship, and/or publication of this article.

\section{Compliance with Ethical Standards}

Conflict of Interest The authors declare that they have no conflicts of interest.

Ethical Approval All procedures performed in this research were in accordance with the ethical standards of the institutional and/or national research committee and with the 1964 Helsinki declaration and its later amendments or comparable ethical standards.

Informed Consent Informed consent was obtained from all individual participants included in the research.

Open Access This article is licensed under a Creative Commons Attribution 4.0 International License, which permits use, sharing, adaptation, distribution and reproduction in any medium or format, as long as you give appropriate credit to the original author(s) and the source, provide a link to the Creative Commons licence, and indicate if changes were made. The images or other third party material in this article are included in the article's Creative Commons licence, unless indicated otherwise in a credit line to the material. If material is not included in the article's Creative Commons licence and your intended use is not permitted by statutory regulation or exceeds the permitted use, you will need to obtain permission directly from the copyright holder. To view a copy of this licence, visit http://creativecommons.org/licenses/by/4.0/.

\section{References}

Anakwah N, Horselenberg R, Hope L, Amankwah-Poku M, van Koppen PJ (2020) Cross-cultural differences in eyewitness memory reports. Appl Cogn Psychol 34(2):504-515. https://doi. org/10.1002/acp.3637

Ananthalakshmi A (2016, November 14). How Malaysia allows child abuse to go unpunished. Reuters. https://www.reuters.com/article/ us-malaysia-sexcrimes-insight-idUSKBN1390AT

Baldwin J (1992). Video-taping of police interviews with suspects: an evaluation. Police Research Series Paper No. 1

Baldwin J (1993) Police interview techniques: establishing truth or proof? Br J Criminol 33(3):325-352. https://doi.org/10.1093/ oxfordjournals.bjc.a048329

Baugerud GA, Magnussen S, Melinder A (2014) High accuracy but low consistency in children's long-term recall of a real-life stressful event. J Exp Child Psychol 126:357-368. https://doi. org/10.1016/j.jecp.2014.05.009

Bruck M, Ceci SJ (1999) The suggestibility of children's memory. Annu Rev Psychol 50:419-439. https://doi.org/10.1146/annurev. psych.50.1.419

Bull R, Rachlew A (2020). Investigative interviewing: From England to Norway and beyond. In S. Barela, M. Fallon, G. Gaggioli, and J. Ohlin (Eds.), Interrogation and torture: research on efficacy, and its integration with morality and legality (pp.171-196). Oxford University Press.
Cheah IG-S, Choo WY (2016) A review of research on child abuse in Malaysia. Med J Malaysia 71(Supplement 1):87-99

Clarke C, Milne R, Bull R (2011) Interviewing suspects of crime: the impact of PEACE training, supervision and the presence of a legal advisor. Journal of Investigative Psychology and Offender Profiling 8(2):149-162. https://doi.org/10.1002/jip.144

Collins R, Lincoln R, Frank MG (2002) The effect of rapport in forensic interviewing. Psychiatr Psychol Law 9(1):69-78. https://doi. org/10.1375/pplt.2002.9.1.69

Cyr M, Lamb ME (2009) Assessing the effectiveness of the NICHD investigative interview protocol when interviewing French-speaking alleged victims of child sexual abuse in Quebec. Child Abuse Negl 33(5):257-268. https://doi.org/10.1016/j.chiabu.2008.04.002

Griffiths A, Milne B (2006). Will it all end in tiers? Police interviews with suspects in Britain. In T. Williamson (Ed.), Investigative interviewing: rights, research, regulation (pp. 167-189). Willan Publishing.

Gudjonsson GH (1992). The psychology of interrogations, confessions and testimony. John Wiley \& Sons.

Henrich J, Heine SJ, Norenzayan A (2010) The weirdest people in the world? Behavioral and Brain Sciences 33(2-3):61-135. https:// doi.org/10.1017/S0140525X0999152X

Hill JA, Moston S (2011) Police perceptions of investigative interviewing: training needs and operational practices in Australia. British Journal of Forensic Practice 13(2):72-83. https://doi. org/10.1108/14636641111134314

Hofstede G (1980). Culture's consequences: international differences in work-related values. Sage.

Hofstede G (2011). Dimensionalizing cultures: the Hofstede model in context. Online Readings in Psychology and Culture, 2(1). https:// doi.org/10.9707/2307-0919.1014

Kassin SM (2014) False confessions: causes, consequences, and implications for reform. Policy Insights Behav Brain Sci 1(1):112-121. https://doi.org/10.1177/2372732214548678

Kassin SM, Gudjonsson GH (2004) The psychology of confessions: a review of the literature and issues. Psychol Sci Public Interest 5(2):33-67. https://doi.org/10.1111/j.1529-1006.2004.00016.x

Kassin SM, Kukucka J, Lawson VZ, DeCarlo J (2014) Does video recording alter the behavior of police during interrogation? A mock crime-and-investigation study. Law Hum Behav 38(1):7383. https://doi.org/10.1037/lhb0000047

La Rooy D, Brubacher SP, Aromäki-Stratos A, Cyr M, Hershkowitz I, Korkman J, Myklebust T, Naka M, Peixoto CE, Roberts KP, Stewart H, Lamb ME (2015) The NICHD protocol: a review of an internationally-used evidence-based tool for training child forensic interviewers. Journal of Criminological Research, Policy and Practice 1(2):76-89. https://doi.org/10.1108/JCRPP01-2015-0001

La Rooy D, Lamb ME, Memon A (2011) Forensic interviews with children in Scotland: a survey of interview practices among police. $\mathrm{J}$ Police Crim Psychol 26(1):26-34. https://doi.org/10.1007/s11896010-9072-9

Lamb ME (2016) Difficulties translating research on forensic interview practices to practitioners: finding water, leading horses, but can we get them to drink? Am Psychol 71(8):710-718. https://doi. org/10.1037/amp0000039

Lamb ME, Orbach Y, Hershkowitz I, Esplin PW, Horowitz D (2007) Structured forensic interview protocols improve the quality and informativeness of investigative interviews with children. Child Abuse Negl 31:1201-1231. https://doi.org/10.1016/j.chiabu. 2007.03.021

Lamb ME, Sternberg KJ, Orbach Y, Hershkowitz I, Horowitz D, Esplin PW (2002) The effects of intensive training and ongoing supervision on the quality of investigative interviews with alleged sex abuse victims. Appl Dev Sci 6(3):114-125. https:// doi.org/10.1207/S1532480XADS0603_2 
Leal S, Vrij A, Vernham Z, Dalton G, Jupe L, Harvey A, Nahari G (2018) Cross-cultural verbal deception. Legal Criminol Psychol 23(2):192-213. https://doi.org/10.1111/lcrp.12131

Loftus EF (2005) Planting misinformation in the human mind: a 30-year investigation of the malleability of memory. Learning and Memory 12:361-366. https://doi.org/10.1101/lm.94705

Magnusson M, Ernberg E, Landström S, Akerhurst L (2020) Forensic interviewers' experiences of interviewing children of different ages. Psychol Crime Law. https://doi.org/10.1080/1068316X. 2020.1742343

Milne B, Bull R (2006). Interviewing victims of crime, including children and people with intellectual disabilities. In M. R. Kebbell \& G. M. Davies (Eds.), Practical psychology for forensic investigations and prosecutions (pp. 7-23). John Wiley \& Sons.

Milne B, Powell M (2010). Investigative interviewing. In J. M. Brown \& E. A. Campbell (Eds.), The Cambridge handbook of forensic psychology (pp. 208-214). Cambridge University Press.

Milne B, Shaw G, Bull R (2007). Investigative interviewing: the role of research. In D. Carson, R. Milne, F. Pakes, K. Shalev, \& A. Shawyer (Eds.), Applying psychology to criminal justice (pp. 65-80). John Wiley \& Sons.

Otgaar H, Howe ML (2019) When children's testimonies are used as evidence: how children's accounts may impact child custodial decisions. J Child Custody 15(4):263-267. https://doi. org/10.1080/15379418.2018.1568721

Peterson C (2012) Children's autobiographical memories across the years: forensic implications of childhood amnesia and eyewitness memory for stressful events. Dev Rev 32(3):287-306. https://doi. org/10.1016/j.dr.2012.06.002

Poole DA, Bruck M, Pipe ME (2011) Forensic interviewing aids: do props help children answer questions about touching? Curr Dir Psychol Sci 20(1):11-15. https://doi.org/10.1177/0963721410388804
Poole DA, Lamb ME (1998). Investigative interviews of children: a guide for helping professionals. American Psychological Association.

Powell MB, Wright R, Clark S (2010) Improving the competency of police officers in conducting investigative interviews with children. Police Pract Res 11(3):211-226. https://doi. org/10.1080/15614260902830070

Rabon D (1992). Interviewing and interrogation. Carolina Academic Press.

Rischke AE, Roberts KP, Price HL (2011) Using spaced learning principles to translate knowledge into behavior: evidence from investigative interviews of alleged child abuse victims. J Police Crim Psychol 26:58-67. https://doi.org/10.1007/s11896-010-9073-8

Saywitz KJ, Larson RP, Hobbs SD, Wells CR (2015) Developing rapport with children in forensic interviews: systematic review of experimental research. Behav Sci Law 33:372-389. https://doi. org/10.1002/bsl.2186

Sharman SJ, Powell MB (2012) A comparison of adult witnesses' suggestibility across various types of leading questions. Appl Cogn Psychol 26:48-53. https://doi.org/10.1002/acp.1793

Sumampouw NEJ, Otgaar H, La Rooy D, de Ruiter C (2020) The quality of forensic child interviewing in child sexual abuse cases in Indonesia. J Police Crim Psychol 35(2):170-181. https://doi. org/10.1007/s11896-019-09342-5

Vrij A, Hartwig M, Granhag PA (2019) Reading lies: Nonverbal communication and deception. Annu Rev Psychol 70(1):295-317. https://doi.org/10.1146/annurev-psych-010418-103135

Publisher's Note Springer Nature remains neutral with regard to jurisdictional claims in published maps and institutional affiliations. 